\title{
Detecting relationships between the interannual variability in ecological time series and climate using a multivariate statistical approach - a case study on Helgoland Roads zooplankton
}

\author{
Hauke Heyen ${ }^{1, *}$, Heino Fock ${ }^{2}$, Wulf G reve ${ }^{2}$ \\ ${ }^{1}$ G KSS Institut für G ewässerphysik, M ax-Planck-Straße, D-21502 G eesthacht, G ermany \\ ${ }^{2}$ Forschungsinstitut Senckenberg, N otkestraße 31, D-22607 Hamburg, G ermany
}

\begin{abstract}
A multivariate statistical approach is presented that allows a systematic search for potential relationships between the variability in ecological time series and climate records. In this study, interannual variability in large- and mesoscale climate variables in the North Sea region is compared with variability in local zooplankton observations from Helgoland. The species Noctiluca scintillans (Protozoa), Temora longicornis and Acartia sp. (Copepoda), and spionid larvae (Polychaeta) are examined. The multivariate model detected several high correlations between zooplankton abundance and winter climate. Based on these correlations, complementary hypotheses about the causal relationships are discussed using available local data.
\end{abstract}

KEY WORDS: Zooplankton · Climate - Variability · North Sea · Empirical Orthogonal Functions . Canonical Correlation

\section{INTRODUCTION}

\subsection{The problem}

Interannual variability in observed ecological time series is sometimes assumed to be driven by variability in climate. However, often no clear knowledge about the driving climatic factors exists. A straightforward way to check the assumed dependence is by comparison of the observed time series with climate data from a local station or an available climate index. Disadvantages of such an approach are: Firstly, single stations contain only limited information. Especially in marine ecology, in which a sample taken at one site might have been advected from another site, information about spatial gradients is of importance. Secondly, if time series of several decades length are examined, data from

*E-mail: heyen@gkss.de a single station are often inhomogeneous or contain missing values. Or, as is the case in the present study, the local observations show a high variability which is caused by local peculiarities, namely high temperature and salinity gradients around Helgoland. Since the zooplankton might have been advected from other sites, the relationship between the 2 data sets is blurred by this local variability. In both cases, the use of data from several stations will improve the analysis, since local inhomogeneity and local variability are smoothed. Third, climate indices are generally not optimized for the field of study examined. For example, the North Atlantic Oscillation Index (NAOI) describes a dominant atmospheric mode, but not necessarily the mode that is most important for Helgoland zooplankton.

In conclusion, if relationships are sought between climate and ecological time series, a multivariate approach possesses several advantages, namely the consideration of spatial gradients, the smoothing of inhomogeneity or variability at single stations and the possibility of optimizing patterns or indices according 
to the field of study examined. The questions are then, firstly, how can a relationship be detected if its nature is not known, and how can patterns or indices be optimized? And, secondly, how can an overdetermination of the relationship be avoided if multiple predictors are used?

\subsection{The solution}

The presented method is a modification of the socalled 'statistical downscaling' approach described by von Storch et al. (1993). This combination of multivariate statistical techniques matches the problems described above: (1) information from fields of predictors and predictands can be related to each other, (2) predictors are optimized with respect to the predictands examined, and (3) the number of model parameters can be kept low.

In this study, different large- and mesoscale climate variables (i.e. variables that characterize the climate over an area several times larger than $10000 \mathrm{~km}^{2}$ ) from the North Sea region are used as predictors, since long and homogeneous records exist. Predictands are locally observed zooplankton abundances at Helgoland. This approach is not unproblematic, since climate variables are compared with biological variables, and regional averages with point observations. In addition, the statistical model possesses no knowledge about physical or biological processes. Furthermore, when the number of parameters of the model are reduced via Empirical Orthogonal Functions (EOFs), variability on small spatial scales is truncated. Considering these aspects, special attention is applied to validating the reasonableness and causality of the detected correlations.

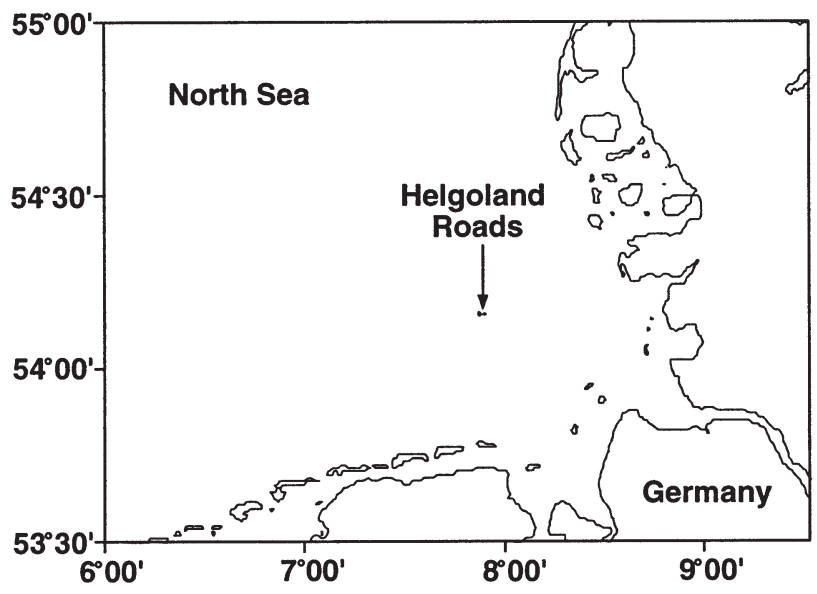

Fig. 1. Position of Helgoland Roads

\section{DATA}

\subsection{Helgoland Roads zooplankton}

Since 1974, mesozooplankton ( $150 \mu \mathrm{m}$ net series) has been sampled 3 times $w^{-1}$ at Helgoland Roads (Fig. 1). A detailed description of the data set is given by Greve \& Reiners (1995).

In this study, Noctiluca scintillans, the metatrochophora larvae of spionids (Polychaeta) and the calanoid copepods Temora longicornis and Acartia sp. are examined. The main criteria for this choice were that these (groups of) species represent different trophic levels and generally exhibit high abundances at Helgoland Roads, and that nearly complete records with weekly resolution exist from 1974 to 1995.

The following 4 different properties of the zooplankton records were examined:

- With $a_{i}$ being the mean abundance in week $i$, the 'log-abundance' $A_{i}$ in that week was computed as

$$
A_{i}=\ln \left(a_{i}+1\right)
$$

The reason for the log-transformation is that the observed abundances vary over 5 orders of magnitude. The log-transformation reduces the variability and shifts the data closer to a Gaussian distribution, which is required for the linear analysis.

- For each year, the 'net increase in log-abundance' was computed by calculating the difference in logabundance between the following different seasons: -J une to J uly mean (of $A_{i}$ ) minus J anuary to February mean (of $A_{i}$ )

-J une to J uly mean minus February to M arch mean -J uly to August mean minus February to M arch mean -J uly to August mean minus M arch to A pril mean -J une to August mean minus February to A pril mean - May to J uly mean minus February to A pril mean.

- For each year, the 'integrated log-abundance' $A_{\text {suml }}$ was computed by summing up $A_{i}$ from week 1 to the end of week I:

$$
A_{\text {suml }}=\sum_{i=1}^{1} A_{i}
$$

For I, monthly steps were selected, i.e. I $=5 \mathrm{~J}$ anuary), 9 (February), ... 52 (December).

- The 'relative increase in abundance' $\Delta a$ was computed. This measure tells whether more increase or more decrease situations occurred in the specific period.

$$
\Delta a_{i}=\frac{a_{i+1}-a_{i}}{M a x}\left(a_{i+1}, a_{i}\right) \begin{cases}M \operatorname{ax}\left(a_{i+1}, a_{i}\right)=a_{i+1} & \text { if } a_{i+1} \geq a_{i} \\ M \operatorname{ax}\left(a_{i+1}, a_{i}\right)=a_{i} & \text { if } a_{i}>a_{i+1}\end{cases}
$$

The relative increase $\Delta a_{\text {i }}$ varies from -1 (extreme decrease around week i) to 0 (no change) to 1 (extreme increase). 


\subsection{C limate data}

\subsubsection{Data used by the multivariate model}

The following data were used as potential predictors:

- Sea surface temperature (SST) on a $2^{\circ} \times 2^{\circ}$ grid from the Comprehensive Ocean Atmosphere Data Set. The selected area extended from $17^{\circ} \mathrm{W}$ to $7^{\circ} \mathrm{E}$ and from $45^{\circ} \mathrm{N}$ to $61^{\circ} \mathrm{N}$.

- Tendencies of SST were calculated by subtracting the latter of 2 successive monthly means from the former.

- Air temperature at $2 \mathrm{~m}$ height $(\mathrm{T})$ on a $5^{\circ} \times 5^{\circ}$ grid (data from the Climate Research Unit, Norwich, UK [CRU]; J ones 1994). The selected area extended from $17.5^{\circ} \mathrm{W}$ to $12.5^{\circ} \mathrm{E}$ and from $42.5^{\circ} \mathrm{N}$ to $62.5^{\circ} \mathrm{N}$.

- Sea level air pressure (SLP) on a $5^{\circ} \times 5^{\circ}$ grid (analysis data from the National Center for Atmospheric Research, Boulder, USA [NCAR]; Trenberth \& Paolino 1980). The selected area extended from $20^{\circ} \mathrm{W}$ to $10^{\circ} \mathrm{E}$ and from $45^{\circ} \mathrm{N}$ to $65^{\circ} \mathrm{N}$. This data set also contains indirect information about advection of temperature and precipitation, storminess and wind direction.

- Tendencies of SLP were calculated by subtracting the latter of 2 successive monthly means from the former.

- Elbe transport (data from the Arbeitsgemeinschaft Elbe, Hamburg, Germany [ARGE]. On an annual time scale, freshwater discharge is highly correlated with the salinity in the German Bight (Heyen \& Dippner 1998).

- Gulf stream index (GSI). This is a measure for the northward extension of the Gulf Stream (Taylor 1995).

- North Atlantic Oscillation Index (NAOI). This index gives the difference between the air pressure at Lisbon (Portugal) and Stykkisholmur (Iceland) in winter. A high index generally coincides with westerly winds and mild winters in Europe (Hurrell 1995).

\subsubsection{Data used for validation}

- SLP variance in the 2.5 to $6 \mathrm{~d}$ frequency band, calculated as a proxy for storm activity (Blackmon 1976).

- Spatially finely resolved SST from the North Sea on a $20 \times 20$ nautical miles grid (data from the Federal $M$ aritime and Hydrographic Agency, Hamburg, Germany [BSH]; Becker \& Pauly 1996).

- Local surface salinity (LS) and sea surface temperature (LT) at Helgoland Roads. These were measured 3 times $w^{-1}$ when the zooplankton samples were taken (Greve \& Reiners 1995).

- Local wind strength and direction at Helgoland
Roads from the German Meteorological Service, Offenbach, Germany. Wind strength (in Beaufort) and direction (8 main directions) were classified after Backhaus (1993) into type 1 (directions S, SW, W), type 2 (NW), type $3(\mathrm{~N}, \mathrm{NE}, \mathrm{E})$ and type $4(\mathrm{SE})$, according to the wind induced circulation patterns. Weekly means for the wind effect for each wind type were calculated as the duration of each wind type multiplied by its strength.

\section{METHOD}

\subsection{Outline of suggested method}

The basic concept of the suggested method is outlined in Fig. 2. The zooplankton is situated at the top of the figure. Since it is unclear which set of zooplankton data is best suited for prediction (e.g. weekly averages? Monthly averages?), a pool of potential predictands is generated (Step 1 in Fig. 2). In the next step,

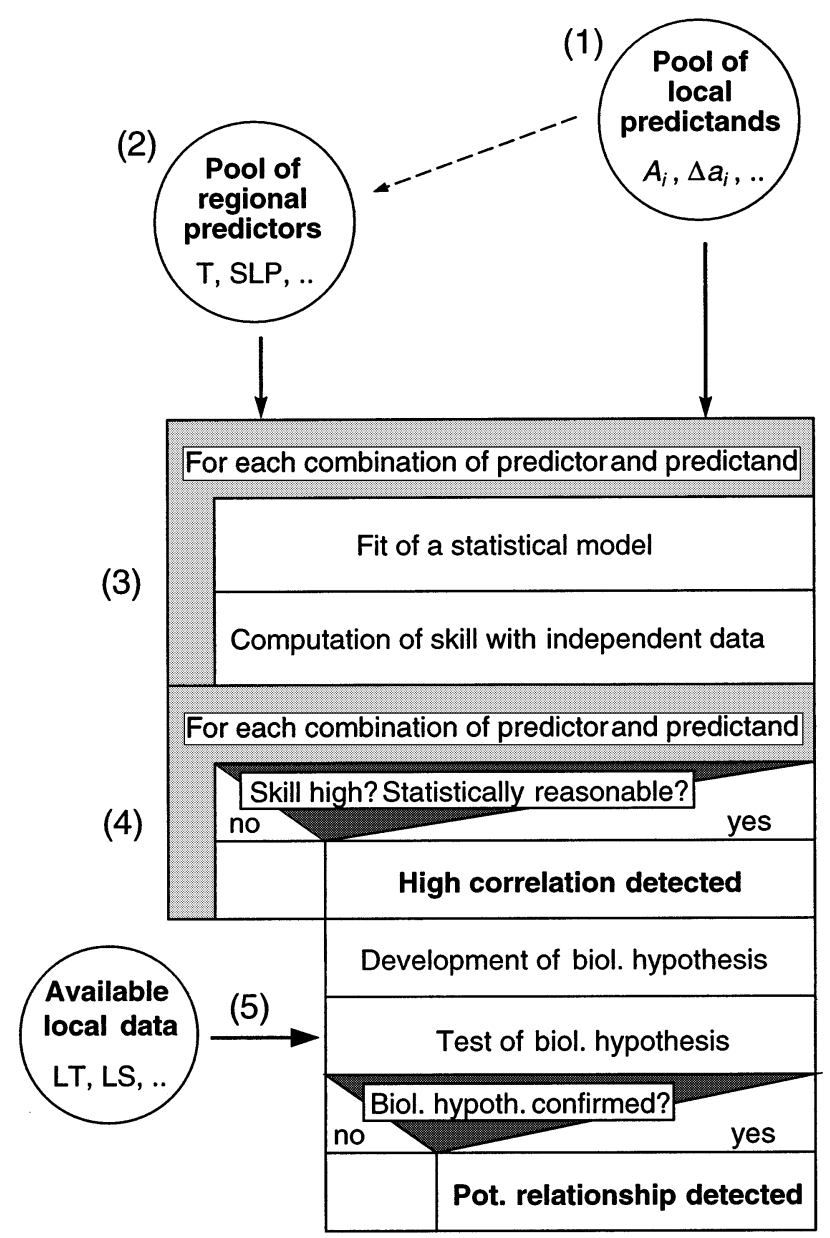

Fig. 2. Outline of the applied method 
potential predictors for the selected predictands are sought (Step 2). A statistical model is fitted and validated to all possible combinations of potential predictors and predictands (Step 3). The result of the validation is a skill factor, i.e. a measure of the quality of the model. The combinations with the highest skills are selected and tested for reasonability (Step 4). The same approach was used by Kröncke et al. 1998.

Special attention was applied to test the biological plausibility of the results. Climate variables on a regional scale were used as predictors (Step 2). If the detected correlations represent causal relationships, correlations between local climate and zooplankton should exist as well, although they might be blurred and, hence, be weaker. Therefore, the detected correlations are used to develop complementary hypotheses about the causal relationships, which are discussed using available local observations (Step 5).

\subsection{Multivariate analysis}

\subsubsection{Processing the data}

Potential predictors are the climate data listed in Section 2.2.1. Potential predictands are log-abundance, net increase, integrated log-abundance and relative increase of $\mathrm{N}$. scintillans, spionid larvae and the 2 copepod species (Section 2.1). Before predictors and predictands were linked to each other, they were processed under the following aspects:

(1) Time scale. It is possible that the relationship occurs at a specific time scale only, e.g. for low-frequency variability. Hence, 1-, 3- and 6-mo running averages of the climate data, and 1-2-1-weighted, 8-wk and 26-wk running averages of log-abundance and relative increase were calculated [1-21-weighted average of log-abundance $A_{i}$ in week $i$ is calculated as $0.25 \times\left(1 \times A_{i-1}+2 \times A_{i}+1 \times A_{i+1}\right)$.

(2) Seasonal cycle. The seasonal cycle is subtracted from all predictands and predictors, since the interannual variability is to be examined.

For the weekly (monthly) climate data, the seasonal cycle was computed by averaging the values in week (month) 1 , in week (month) 2 , and so on. For the zooplankton data, the seasonal cycle was calculated analogously, but based on 1-2-1weighted running averages of weekly data, due to the high variability from week to week.

For each selected combination of potential predictor and predictand, statistical models were calculated under the following aspects:

(3) Seasonal succession. It is likely that the relationship between predictor and predictand depends on the season. Therefore, one statistical model was com- puted for each season. For example, one model was built between climate in J anuary and zooplankton in J anuary, another model was built between climate in February and zooplankton in February, etc.

(4) Time lag. A temporal lag might exist between the climate signal and its impact on the zooplankton. Therefore, Step 3 was computed including all time lags within $\pm 1 \mathrm{yr}$. It is assumed that a causal relationship between climate and zooplankton lasts for a narrow range of time lags only; for example, a relationship between SST and abundances in J une is highest for J une SST, weakens for M ay SST and is not present for SST in earlier months. Of course, it should not be present for J uly SST as well. In this sense, the testing of several time lags-including lags where the signal in zooplankton precedes the signal in climate-can yield information as to whether detected correlations are significant or whether they occur randomly.

\subsubsection{Fitting of model}

For each chosen combination of predictor and predictand, the model was built in the following way: Firstly, Empirical Orthogonal Functions (EOFs, also known as 'Principal Components') of the predictor and the predictand are calculated. A feature of this transformation is that the 1st EOF describes the maximum variance of the investigated variable, the 2 nd EOF the maximum variance orthogonal to the 1st EOF, and so on. This technique is used to reduce the number of parameters of the model.

For example, the selected SLP field contains 35 grid points, i.e. 35 variables are necessary to describe the monthly variance within this field. The 4 leading EOFs explain around $45,30,15$ and $5 \%$ of this variance. Thus, it is possible to use 4 variables instead of 35 to reconstruct $95 \%$ of the observed SLP variance. Therefore, by using the leading EOFs of the predictor and predictand in the following computations, the number of parameters of the model is kept low, even though information from many grid points is used. The loss of information due to the truncation of trailing EOFs is moderate and restricted to variability on small spatial scales, i.e. single grid points. For more information on EOFs refer to Preisendorfer (1988).

Secondly, a Canonical Correlation Analysis (CCA) is performed between the leading EOFs of the climate predictor and zooplankton predictand. The CCA identifies a climate pattern $\vec{C}$ and time series $\vec{C}$, and a zooplankton pattern $\vec{P}$ and time series $\vec{p}$ (von Storch 1995). $\vec{c}$ and $\vec{p}$ are optimally correlated to each other. The detected pattern $\vec{C}$ can be interpreted as a signal in the climate that coincides with a 
signal $\vec{P}$ in the zooplankton (see e.g. Fig. 4), while the degree of coincidence is given by the correlation between $\vec{c}$ and $\vec{p}$.

In this study, the CCA is calculated using the 1st EOF of zooplankton, which describes between $80 \%$ (if 2 species are concatenated into 1 vector) and 100\% (if 1 single species is examined) of the zooplankton observations $\vec{P}_{\text {obs. }}$. Hence, if $\mathrm{P}_{\text {obs }}(s, t)$ is the observation of species $s$ at time $t, P(s)$ is the value of the CCA pattern for species $s$, and $p(t)$ is the value of the time series for time t,

$$
\mathrm{P}_{\mathrm{obs}}(\mathrm{s}, \mathrm{t}) \approx \mathrm{P}(\mathrm{s}) \times \mathrm{p}(\mathrm{t})
$$

\subsubsection{Validation of model}

CCA correlations were optimized with respect to the sample examined. Thus, the obtained correlations were biased and it was necessary to validate the model with independent data. Here, a cross-validation approach (Michaelsen 1987) was chosen: if $n$ time steps of data are available, $n$ models are fitted by using $\mathrm{n}-1$ different time steps each. For each model, the zooplankton of the nth step is regressed from climate. Let $\rho$ be the correlation coefficient between $\vec{c}$ and $\vec{p}$. According to Eq. (1) the estimation of species s for time $\mathrm{t}$ is then

$$
\mathrm{P}_{\mathrm{est}}(\mathrm{s}, \mathrm{t}) \approx \mathrm{P}(\mathrm{s}) \times \rho \times \mathrm{c}(\mathrm{t})
$$

where $c(t)$ is the value of the CCA time series of the predictor for time t. Finally, the $n$ estimations are compared with the observations. For more details on this regression refer to Heyen et al. (1996).

\subsubsection{Skill factor}

The results were preselected according to their skill. As skill factors, correlation coefficient $r$ and the Brierbased score against the relative climatology $\beta$ were used.

$$
\beta=1-\frac{\operatorname{Var}\left(\overrightarrow{\mathrm{P}}_{\mathrm{obs}}-\overrightarrow{\mathrm{P}}_{\mathrm{est}}\right)}{\operatorname{Var}\left(\overrightarrow{\mathrm{P}}_{\mathrm{obs}}\right)}
$$

with $\vec{P}_{\text {obs }}$ and $\vec{P}_{\text {est }}$ being the observations and estimations of the predictand, and $\operatorname{Var}()$ being the variance. $\beta=1$ means that observations and estimations are identical, and $\beta=0$ that the error of the estimations has the same size as the variance of the observations (Livezey 1995).

A 'high' $r$ and $\beta$ in the cross-validation indicates a high correlation that is robust against the chosen sample used for fitting. 'High' is defined relatively, i.e. against the skill level reached for other time lags (this is why a wide range of time lags is tested; see Section
3.2.1). The reason is that the value of the skill varies with the length and autocorrelation of the respective time series.

\subsubsection{Evaluation of results}

Results that possess a high skill were evaluated as follows:

- If the signal in the zooplankton occurs before the signal in climate, the results were discarded, since they were obviously nonsensical. However, high correlations were extremely seldom for such nonsensical time lags and were always caused by strong lowfrequency variability.

- The significance level (>95\%, >99\%) of selected results was determined by generating 10000 series of random numbers with the same statistical properties (mean, variance, autocorrelation) as the EOF time series of the predictor. These time series were related by CCA to the predictands. Afterwards the number of these random correlations that had a higher skill than the selected result was counted. Thus, it was verified that the high skill of a selected correlation was not caused by shortness of or trends in the respective time series.

- If it is assumed that the relationship between predictor and predictand is indirect, associated patterns (Heyen et al. 1996) may help to identify the missing link. For example, if a correlation between SLP and zooplankton is found and it is assumed that storm activity causes this relationship, a high amount of variance of storm activity should be correlated to the CCA time series of SLP and zooplankton.

\subsection{C omplementary hypotheses}

In the present study, regional climate data were linked to local zooplankton observations. If the detected correlations represent causal relationships, correlations on a local scale should exist as well. Therefore, the results of the multivariate model were used to develop a complementary hypothesis which is based on the existing knowledge of biological and environmental factors. Only a few selected effects, which were assumed to be of first-order influence, are involved in the hypothesis. The hypothesis was discussed using available local data. For this purpose, the correlation matrix and a qualitative response model were computed.

The qualitative response model uses coarsely resolved ordinal data and logistic regression (J obson 1992) in order to see whether correlations exist, even if the data are blurred. The variables $y$ are transformed 
Table 1. Description of the detected correlations and skill of the best model. SST: sea surfce temperature; SLP: sea level pressure; NAOI: North Atlantic Oscillation Index

\begin{tabular}{|llll|}
\hline & Predictand & Predictor \\
\hline Noctiluca scintillans & Summer log-abundance & Winter SST & Skill \\
& Winter to summer integrated log-abundance & Winter SST & $r=0.72$ \\
Spionid larvae & Winter to summer net increase of log-abundance & Winter SST & $r=0.75$ \\
Temora longicornis & Winter log-abundance & Winter SLP & $r=0.91$ \\
& Winter log-abundance & Winter NAOI & $r=0.62$ \\
\hline
\end{tabular}

into the 4-level ordinal variables 'very low' for $y \leq \bar{y}-$ $\sigma(\bar{y}$ is the mean, $\sigma$ is the standard error), 'low' for $\bar{y}-\sigma$ $<y \leq \bar{y}$, 'high' for $\bar{y}+\sigma>y>\bar{y}$, and 'very high' for $\mathrm{y} \geq$ $\bar{y}+\sigma$. The model was computed in a forward selection modus (SAS 1994). The forward selection technique selects the effect (i.e. the predictor variable) which leads to the highest F-statistic. In a second step, a second predictor variable is added. Again, it is selected such that the F-statistic is highest. Interactions between 2 effects are allowed by multiplying them with each other. Care was taken that this multiplication did not reverse the sign of the original effects ( 2 negative effects give a negative effect). The contribution of each of the variables to the variance of the model is calculated and p-values according to the $\mathrm{F}$-statistics are given.

\section{RESULTS}

Table 1 shows the most outstanding of the detected correlations between zooplankton and climate. In the following, these correlations are discussed in detail.

\subsection{Noctiluca scintillans}

\subsubsection{Detected correlation}

Three different correlations were detected between SST and Noctiluca scintillans (Table 1). However, since the highest abundances of $\mathrm{N}$. scintillans occur in summer, the variables 'log-abundance in summer', 'integrated log-abundance from winter to summer' and 'net increase of log-abundance between winter and summer' all depend on the height of abundance in summer. Hence, the 3 detected correlations in Table 1 all represent similar information.

Fig. 3 shows the skill of a model that uses 3 SST EOFs to estimate the integrated log-abundance of Noctiluca scintillans. The skill is highest for winter SST and winter to summer abundances (' $D$ ' in Fig. 3 ). The reason for the high skills in autumn is the low abundance of $\mathrm{N}$. scintillans then which hardly changes the value of the integrated abundance.

The relationship ' $D$ ' is shown in Fig. 4. The leading 3 EOFs of the November to J anuary SST field are used to estimate the integrated log-abundance of Noctiluca scintillans from J anuary to J uly. The skill of the model is $r=0.75$ and $\beta=0.56$, which is significantly higher than the $99 \%$ confidence level $\left(r_{99}=0.6, \beta_{99}=0.3\right)$. The SST CCA pattern shows an anomalously cold North Sea that coincides with anomalously low abundances of $\mathrm{N}$. scintillans. In the same way, a warm North Sea coincides with high abundances.

To examine the detected correlation more closely, EOFs of the finely resolved North Sea SST were correlated with Noctiluca scintillans. It was found that the 1st EOF of SST from November to J anuary - which shows an entirely warm or cold North Sea with largest anomalies in the southeast-contained all of the important information by itself, and that the usage

Fig. 3. Skill of the model if the 3 leading SST EOFs are used to estimate the integrated log-abundance of Noctiluca scintillans. (a) 1-, (b) 3- and (c) 6-mo averages of SST. Each plot depicts $r$ (lower half) and $\beta$ (upper half) in terms of end month of integration (y-axis) and time lag to the climate field ( $x$-axis, lag ' 0 ' is defined as 'J anuary in the same year', ' +1 ' as 'February', etc.). Skill is highest for winter SST and integrated log-abundance in summer ('D') 
(a)

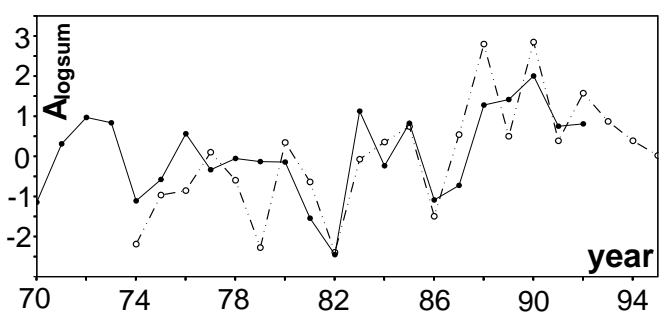

(b)

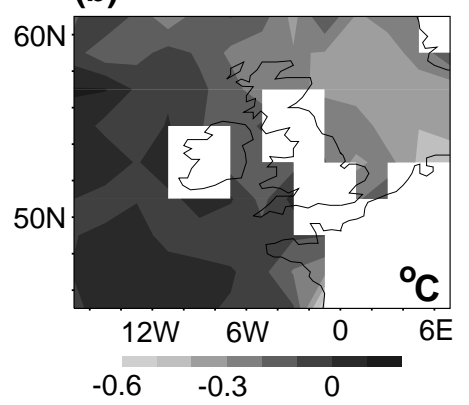

Fig. 4. (a) Estimated (solid) and observed (dot-dashed) anomalies of the integrated log-abundance of Noctiluca scintillans from J anuary to July. The estimations were derived from the 3 leading EOFs of the November to J anuary SST. (b) SST CCA pattern showing an anomalously cold North Sea, which is correlated with anomalously low logabundances of -1.5 of more SST EOFs did not improve the model significantly. The correlation between the 1st EOF of SST and the time series of $N$. scintillans was already $r=$ 0.63. The conclusion is that the detected correlation is based on the simple signal 'warm N orth Sea in winter' or 'cold North Sea in winter' and that spatial details play only a minor role.

\subsubsection{Causal relationship}

Noctiluca scintillans is a unicellular, short-lived member of the holoplankton, i.e. it spends its complete life cycle in the water column. It has been described as a voracious feeder on phyto- and zooplankton, and its population may increase exponentially and double within a few days. It can have several abundance peaks within the year (Uhlig \& Sahling 1990). Exceptionally high densities are referred to as 'red tides' (Schaumann et al. 1988, Elbrächter \& Qi 1998).

The multivariate model detected a high correlation between winter SST and summer abundances of Noctiluca scintillans (Table 1). Due to the short life time of this species it is unlikely that the spring or summer abundances are directly linked to the winter
SST. Evidence exists that other holoplanktic species like the arrow-worm Sagitta sp. and the ctenophore Pleurobrachia pileus have negative influence on the development of $\mathrm{N}$. scintillans (Fock unpub.). If these species are influenced by SST, changed interactions with $\mathrm{N}$. scintillans will result. Whereas P. pileus blooms earlier than N. scintillans, Sagitta sp. is an autumn species. Therefore, the complementary hypothesis is:

1. High water temperatures lead to an earlier start of the growth period of Pleurobrachia pileus. The earlier the start of the growth period of P. pileus and the later the start of the growth period of Sagitta sp. in relation to the growth period of $\mathrm{N}$. scintillans, the higher the maximum abundance of $\mathrm{N}$. scintillans.

The correlation matrix (Table 2) shows a significant correlation between low water temperature at $\mathrm{Hel}$ goland in weeks 1 to $13\left(\mathrm{LT}^{1-13}\right)$ and a late maximum of adult Pleurobrachia pileus. Furthermore, a significant correlation exists between a late maximum of adult $P$. pileus and a late maximum of Noctiluca scintillans. This can be explained by the the fact that both species are correlated with $\mathrm{LT}^{1-13}$, but it could also mean that the later P. pileus blooms, the later N. scintillans finds good conditions in which to bloom. The latter explana-

Table 2. Correlation matrix. Correlation coefficients in bold: significant at $* * p<0.01$ and $* p<0.05$. Ns ${ }^{\text {week}}$, Ns ${ }^{\text {max}}$ : week and height of maximum abundance of Noctiluca scintillans; $\mathrm{Pp}_{\mathrm{juv}}^{\text {week }}, \mathrm{Pp}_{\mathrm{juv}}^{\max }$ and $\mathrm{Pp}$ ad week, $\mathrm{Pp}_{\mathrm{ad}}^{\max }$ : week and height of maximum abundance of juvenile and adult Pleurobrachia pileus; Ss ${ }^{\text {week }}, \mathrm{Ss}^{\text {max: }}{ }^{\text {week }}$ and height of maximum abundance of Sagitta $\mathrm{Sp}$; $\mathrm{LT}^{1-13}$ : mean water temperature at Helgoland in Weeks 1 to 13

\begin{tabular}{|c|c|c|c|c|c|c|c|c|c|}
\hline & $\mathrm{Ns}{ }^{\text {week }}$ & $\mathrm{Ns}^{\max }$ & $\mathrm{Pp}_{\mathrm{juv}}^{\text {week }}$ & $\mathrm{Pp}_{j \mathrm{ju}}^{\max }$ & Pp week & $\mathrm{Pp}_{\mathrm{ad}}^{\max }$ & Ss ${ }^{\text {week }}$ & $\mathrm{Ss}^{\max }$ & $\mathrm{LT}^{1-13}$ \\
\hline $\mathrm{Ns}^{\text {week }}$ & 1 & & & & & & & & \\
\hline $\mathrm{Ns}^{\max }$ & -0.11 & 1 & & & & & & & \\
\hline $\mathrm{Pp}_{\mathrm{puv}}^{\text {week }}$ & 0.15 & 0.25 & 1 & & & & & & \\
\hline $\mathrm{Pp}_{\text {juv }}^{\max }$ & 0.42 & -0.06 & 0.20 & 1 & & & & & \\
\hline $\mathrm{Pp}_{\mathrm{ad}}^{\text {week }}$ & $0.59 * *$ & -0.24 & 0.17 & 0.31 & 1 & & & & \\
\hline $\mathrm{Pp}_{\mathrm{ad}}^{\max }$ & 0.38 & -0.17 & 0.27 & 0.08 & 0.33 & 1 & & & \\
\hline Ss week & 0.25 & 0.23 & 0.26 & 0.08 & 0.14 & 0.26 & 1 & & \\
\hline $\mathrm{Ss}^{\max }$ & 0.33 & -0.04 & 0.12 & 0.38 & 0.23 & 0.17 & -0.12 & 1 & \\
\hline $\mathrm{LT}^{1-13}$ & -0.43 & 0.03 & -0.21 & -0.12 & $-0.48 *$ & -0.28 & -0.37 & -0.12 & 1 \\
\hline
\end{tabular}


tion is supported by the fact that high correlations exist between a late maximum of $\mathrm{N}$. scintillans and high maxima of adult and juvenile P. pileus, which are not correlated with $\mathrm{LT}^{1-13}$ (Table 2). Hence, evidence exists that the timing of $\mathrm{N}$. scintillans depends not only on $\mathrm{LT}^{1-13}$, but on the timing and maximum of P. pileus as well.

To examine the maximum abundance of Noctiluca scintillans more closely, the response model was calculated. As predictors, the variables from Table 2 were used. Furthermore, combined effects of $\mathrm{LT}^{1-13}$ and Pleurobrachia pileus or Sagitta sp. were allowed. It was found that the combined effect of $\mathrm{LT}^{1-13}$ and the week of maximum abundance for adult $P$. pileus is the most significant predictor $(p=0.005)$. The second best predictor is the week of maximum for juvenile $P$. pileus $(p=0.17)$.

Since $\mathrm{LT}^{1-13}$ is highly correlated with the $\mathrm{J}$ anuary to $M$ arch average of abundances of adult $P$. pileus ( $r=$ $0.63, p=0.003$, not shown), these results indicate that the timing and abundance of $P$. pileus influence the maximum abundance of $\mathrm{N}$. scintillans.

In summary, evidence exists that high water temperatures in winter lead to an earlier start of the growth season of Pleurobrachia pileus, and that a late timing or high abundances of P. pileus lead to late timing and low abundances of Noctiluca scintillans. Hence, the result of the multivariate model seems reasonable.

\subsubsection{Outlook}

The result of the multivariate model leads to the question of whether winter SST can be used to estimate the abundance of Noctiluca scintillans in the following year. Furthermore, the simplicity of the predictor (cold or warm North Sea in winter) implies that the correlation could be valid for $\mathrm{N}$. scintillans populations at other sites as well. Therefore, historical and actual winter SST will be used to reconstruct the expected abundances of $\mathrm{N}$. scintillans for past decades up to today. Extremes in this estimated curve will be compared with available historical observations and observations from other sampling sites.

\subsection{Spionid larvae}

\subsubsection{Detected correlation}

A high correlation exists between the log-abundance of spionid larvae in winter and the 3 leading EOFs of the winter SLP. The skill is highest between the $\mathrm{J}$ anuary to February mean of log-abundance and the November to J anuary mean of SLP ( $r=0.91, \beta=$ 0.76 ), and this is clearly above the $99 \%$ confidence level obtained for 10000 Monte-Carlo simulations $\left(r_{99}=0.6, \beta_{99}=0.3\right)$.

The information in the SLP is contained in the 2 leading EOFs, which explain 45 and $37 \%$ of SLP variance, respectively; hence, the important information is large scale. Fig. 5a shows the comparison of the observed and estimated log-abundance of spionid larvae, if 2 SLP EOFs are used as predictors. The skill of the model is $r=0.86$ and $\beta=0.71$. The SLP CCA pattern (Fig. 5b) shows a gradient with low pressure anomalies in the north and high pressure anomalies in the south. This gradient coincides with an anomalously high number of spionid larvae.

The associated pattern of storm activity (not shown) does not explain more than $5 \%$ of the variance at any point in the North Sea; hence, storm activity can be excluded as a possible cause for this relationship. A possible mediator between SLP and spionid larvae is local SST. In the coastal areas of the southeastern N orth Sea, around $50 \%$ of SST variance is associated with the identified SLP CCA pattern (Fig. 6). The regional limitation of the SST signal to the coastal zone explains why no direct relationship between the spionid larvae and the coarsely resolved SST data was found.

(a)
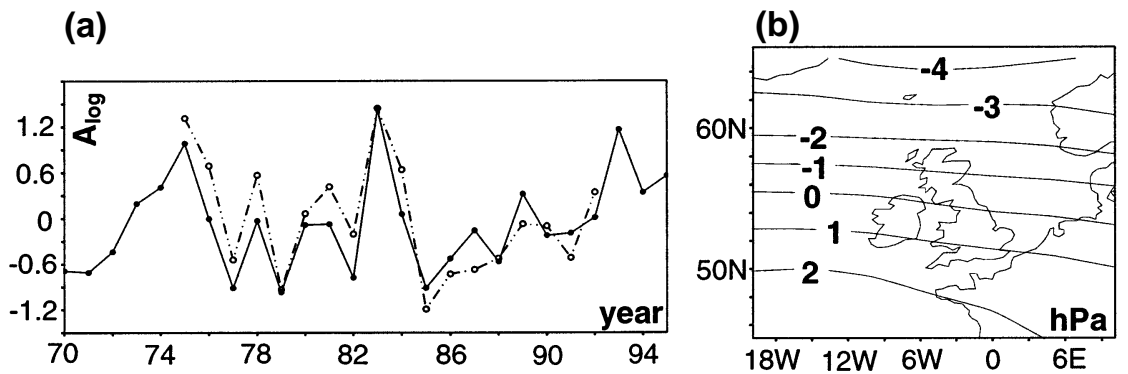

Fig. 5. (a) Estimated (solid) and observed (dot-dashed) anomalies of the J anuary to February log-abundance of spionid larvae. The estimations were derived from the 2 leading EOFs of the December to February SLP. (b) SLP CCA pattern, which explains $40 \%$ of SLP variance and shows a gradient with negative pressure anomalies in the north and positive pressure anomalies in the south, which coincides with an anomalously high log-abundance of +0.7 
(a)

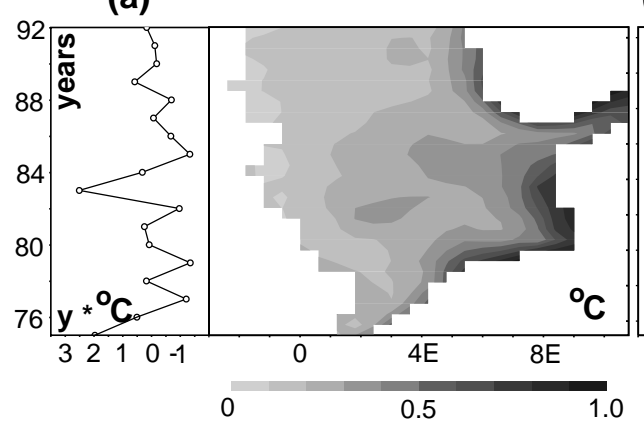

(b)

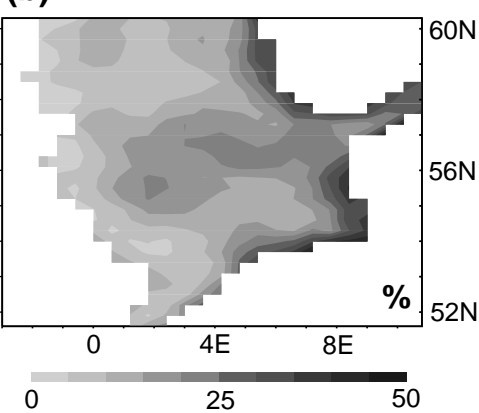

Fig. 6. (a) December to February SST associated with the SLP CCA-pattern from Fig. 5. The temperatures for a specific year can be obtained by multiplying the value in the pattern with the time coefficient (shown on left) of that year. (b) In the coastal zones of the southeastern North Sea, temperature anomalies between $+3^{\circ} \mathrm{C}(1983)$ and $-1.5^{\circ} \mathrm{C}(1985)$ are associated with the SLP pattern and explain $50 \%$ of the SST anomalies. A second maximum in the central North Sea explains about $20 \%$ of variability

\subsubsection{Causal relationship}

Spionid larvae belong to the meroplankton, which spend only part of their lifetime in the pelagic environment. Thus, their planktonic occurrence mainly depends on processes which affect the mature benthic adult population. The maximum abundance of the larvae is reached during spring and summer, and only a small portion of the annual population is captured in $J$ anuary and February. From the ca 20 species which are aggregated into the group of spionid larvae, few spawn in these months; hence, the following results are not representative of the whole group. The multivariate model detected a correlation between high abundances of spionid larvae in J anuary and February and a SLP gradient in the months December to February that indicates westerly winds (Fig. 5). In addition, it was shown that high abundances coincide with a high SST in the coastal zones (Fig. 6). A straightforward explanation for the detected correlation would be that 1. Spionid larvae are advected to Helgoland by westerly winds.

A more complex explanation that includes the detected correlation with coastal SST would be that

2. A high SST affects the maturation of the benthic adult population in the coastal zone and causes an increased abundance of larvae, which are then advected to Helgoland.

In winter, notable populations of spionid larvae exist in the central and southern North Sea (Krause et al. 1995), probably originating from benthic populations at the Dogger Bank. From M arch on, the development of the coastal Wadden Sea populations contributes to the Helgoland spionids (Greve \& Fock unpubl.). Thus, both hypotheses, an advection of larvae from the southern North Sea or an early development of the Wadden Sea population, seem reasonable.
To test these hypotheses, we correlated the observed abundances of spionids with local wind, temperature and salinity. The idea was that the local variables might reveal a simple relationship that helps to identify the origin of the larvae, for example 'high abundances coincide with westerly winds, high temperatures and high salinities'. In this example, the larvae would stem from the southern $\mathrm{N}$ orth Sea, which is indicated by the advection of warm and haline water. The search for such simple relationships can be justified with the results of Backhaus (1980, 1993), who classified the North Sea circulation into 4 types according to the prevailing wind field. According to his results, northwesterly ('type 2') and southeasterly ('type 4') winds cause enhanced on- and offshore transport in the German Bight. Hence, northwesterly and southeasterly winds might lead to an advection of water from the southern North Sea or from coastal areas to Helgoland, respectively.

The correlation matrix (Table 3 ) shows 3 significant correlations between the $J$ anuary to February means of wind ( $\mathrm{W}^{0}$ to $\mathrm{W} 4^{0}$, classified into 4 types according to Backhaus 1993), temperature $\left(\mathrm{LT}^{\circ}\right)$ and salinity $\left(\mathrm{LS}^{\circ}\right)$. None of these variables is significantly correlated with the abundance of spionids in J anuary and February $\left(\mathrm{Sp}^{\mathrm{ab}}, \mathrm{Sp}_{\log }^{\mathrm{ab}}\right)$. No simple relationship between northwesterly or southeasterly winds $\left(\mathrm{W} 2^{\circ}, \mathrm{W} 4^{\circ}\right)$ and water from the southern N orth Sea or of coastal origin exists either.

The lack of a simple relationship can be explained by the fact that Backhaus (1980 1993) described only the principal patterns of the circulation. A frontal resolving model of the German Bight by Dippner (1995) reveals that wind driven gyres and frontal systems cause high variability in the Helgoland region. Due to fluctuations in the plume of the Elbe river, salinity observations at Helgoland are especially inconclusive, while high tem- 
Table 3. Correlation matrix. Correlation coefficients in bold: significant at ***p $<0.001, * * p<0.01$ and $* p<0.05$. Sp ${ }^{\text {ab }}, \mathrm{Sp}_{\text {log: }}^{\text {ab }}$ mean abundance and log-abundance of spionid larvae in Weeks 1 to $8 . \mathrm{W1}^{\circ}, \mathrm{W} 2^{\circ}, \mathrm{W} 3^{\circ}, \mathrm{W} 4^{\circ}$ : wind strength and direction at $\mathrm{Helgoland}$ in Weeks 1 to 8, classified after Backhaus (1993) into 4 types; superscript indicates a timelag of 0 mo, i.e. an average over Weeks 1 to 8. $\mathrm{LS}^{0}$ : salinity at Helgoland Roads in Weeks 1 to 8 . $\mathrm{LT}^{0}, \mathrm{LT}^{-2}, \mathrm{LT}^{-4}$ : water temperature at Helgoland for time lags 0 mo (Weeks 1 to 8), -2 mo (preceding Weeks 45 to 52 ) and -4 mo (preceding Weeks 35 to 52)

\begin{tabular}{|c|c|c|c|c|c|c|c|c|c|c|}
\hline & $S p^{a b}$ & $\mathrm{Sp}_{\log }^{\mathrm{ab}}$ & $W 1^{0}$ & $w 2^{0}$ & $w 3^{0}$ & $W 4^{0}$ & $\mathrm{LS}^{0}$ & $\mathrm{LT}^{0}$ & $\mathrm{LT}^{-2}$ & $\mathrm{LT}^{-4}$ \\
\hline$S p^{a b}$ & 1 & & & & & & & & & \\
\hline $\mathrm{Sp}_{\mathrm{log}}^{\mathrm{ab}}$ & $0.88^{* * * *}$ & 1 & & & & & & & & \\
\hline$W 1^{\circ}$ & 0.14 & 0.08 & 1 & & & & & & & \\
\hline$w 2^{0}$ & 0.29 & 0.34 & 0.38 & 1 & & & & & & \\
\hline$w 3^{0}$ & -0.26 & -0.22 & $-0.83^{* * *}$ & $-0.60^{* *}$ & 1 & & & & & \\
\hline$W 4^{0}$ & 0.00 & 0.04 & $-0.46 *$ & -0.18 & 0.18 & 1 & & & & \\
\hline $\mathrm{LS}^{0}$ & -0.05 & -0.25 & -0.21 & -0.35 & 0.15 & $0.46 *$ & 1 & & & \\
\hline $\mathrm{LT}^{0}$ & 0.14 & 0.29 & $0.59 * *$ & 0.35 & $-0.63^{* *}$ & -0.17 & -0.18 & 1 & & \\
\hline $\mathrm{LT}^{-2}$ & -0.09 & -0.07 & 0.17 & -0.21 & -0.02 & 0.02 & 0.10 & 0.10 & 1 & \\
\hline $\mathrm{LT}^{-4}$ & $0.48 *$ & 0.40 & 0.26 & 0.26 & -0.26 & -0.18 & -0.16 & $0.53^{*}$ & -0.12 & 1 \\
\hline
\end{tabular}

peratures might indicate water from deeper regions (Greve \& Fock unpubl.).

An interesting result is the significant correlation between the abundance of spionids in January and February and the average temperature at $\mathrm{Helgol}$ and in the preceding September to December $\left(\mathrm{LT}^{-4}\right.$, see Table 3). This variable was tested since a time lag between the impact of temperature on benthic spionids and the production of larvae has to be considered. The response model, tested with all variables from Table 3, including combined effects, reveals that the combined effect of $\mathrm{LT}^{-4}$ and $\mathrm{W} 2^{0}$ is the most significant predictor for the abundance of spionids $(p=$ 0.002 , not shown). Since $\mathrm{LT}^{-4}$ is highly correlated with 4 mo averages of water temperature elsewhere in the southern North Sea and German Bight (not shown), a possible explanation could be that (1) warm temperatures in autumn favour maturation and gonadal production of the benthic adult population and that (2) the larvae are advected to Helgoland by favourable currents due to type 2 wind effects. W $2^{0}$ is positively correlated with $\mathrm{LT}^{0}$ (Table 3 ) and high tide gauges at $\mathrm{Hel}$ goland ( $p=0.002$, not shown), which might indicate an onshore transport of water from the southern North Sea, as postulated by Backhaus $(1980,1993)$. However, these relationships are highly speculative. Furthermore, this explanation contradicts the associated SST pattern (Fig. 6), which indicates (1) a temperature influence in the months December to February (according to Table 3, no correlation between spionids and $\mathrm{LT}^{0}$ or $\mathrm{LT}^{-2}$ exists), which (2) is highest in the coastal areas, not in the southern North Sea.

In conclusion, observations of spionid populations in the Wadden Sea (Greve \& Fock unpubl.) and the southern North Sea (Krause et al. 1995) indicate that it is possible that the detected correlations between spionids and air pressure (Fig. 5) or SST (Fig. 6) are real. However, it is obviously no easy task to identify the origin of the spionids caught by a linear correlation of observed wind, temperature and salinity. Therefore, the complementary hypotheses can neither be proved nor rejected.

\subsubsection{Outlook}

The Institute of Oceanography of the University of Hamburg and the Forschungsinstitut Senckenberg are currently cooperating to try to reconstruct the trajectories of the water parcels that are advected to Helgoland. For this purpose, a finely resolved hydrographic model of the German Bight is driven with observed atmospheric fields. This model might help to answer the question of where the caught spionid larvae originate from.

\subsection{Temora longicornis}

\subsubsection{Detected correlation}

Fig. 7 shows that a correlation maximum exists between the log-abundance of Temora longicornis in winter and the NAOI in the same period. The highest skill exists between the NAOI and the J anuary to February mean of log-abundance. This combination is shown in Fig. 8. The obtained skill is $r=0.62$ and $\beta=$ 0.38 , which is slightly higher than the $99 \%$ confidence level ( $r_{99}=0.6$ and $\beta_{99}=0.2$ ). An anomalously high $\mathrm{NAOI}$ coincides with an anomalously high abundance 


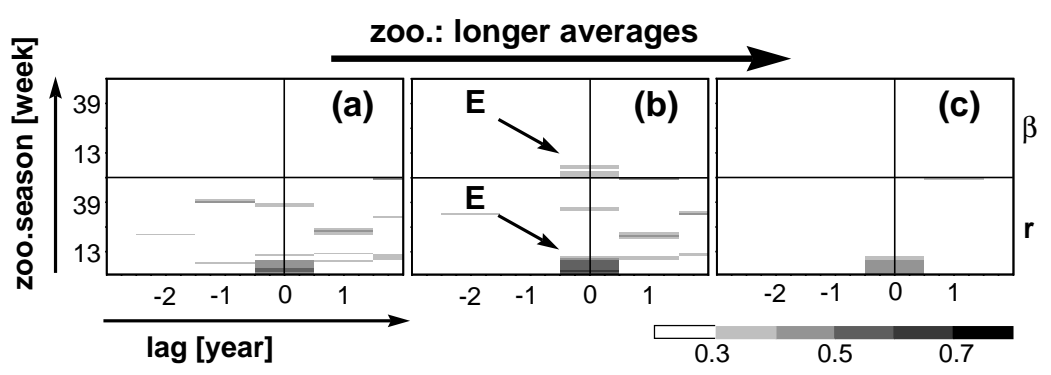

Fig. 7. Skill of the model if the NAOI is used to estimate the integrated logabundance of Temora longicornis. (a) 1-2-1-weighted, (b) 8-wk and (c) 26-wk averages of log-abundance of T. Iongicornis. Each plot depicts $r$ (lower half) and $\beta$ (upper half) in terms of zooplankton season (y-axis) and the time lag to the NAOI (' 0 ' is defined as 'NAOI in the preceding winter', ' +1 ' as 'NAOI in the succeeding winter', etc.). Skill is highest for NAOI and winter log-abundances in the same year ('E')

of T. Iongicornis and, in the same way, a weak NAOI coincides with low abundances.

The NAOI is closely related to the North Sea SST in late winter and spring (Becker \& Pauly 1996, Dippner 1998, Kröncke et al. 1998). A relationship between the NAOI, winter SST and 2 copepod species is described by Fromentin \& Planque (1996). However, only about $20 \%$ of the December to February SST in the southeastern North Sea are associated with the J anuary to February log-abundance of Temora longicornis (not shown). This low percentage might indicate that SST is not a first-order influence on T. longicornis. Furthermore, an influence of storm activity is not likely, since its associated pattern does not explain more than $5 \%$ of the variance at any point in the North Sea (not shown). No correlation exists between Elbe run-off and T. longicornis (not shown).

\subsubsection{Causal relationship}

Calanoid copepods belong to the holoplankton, which reproduces continuously throughout the whole

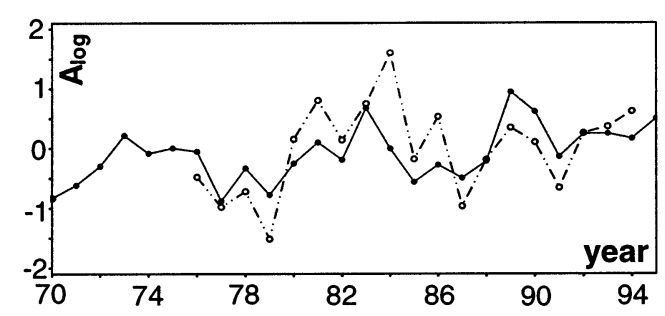

Fig. 8. Estimated (solid) and observed (dot-dashed) anomalies of the J anuary to February log-abundance of Temora longicornis. Estimations were derived from the NAOI. A NAOI anomaly of +1 is correlated with an anomalous logabundance of +0.4 year. Compared to A cartia sp., Temora longicornis is more widespread and more abundant in the southern North Sea (Krause \& Martens 1990). The multivariate model suggested that a high NAOI-which generally coincides with a high SST - leads to high winter abundances of $\mathrm{T}$. longicornis early in the year (Fig. 8). As a possible link, probably not first-order, a high SST was suggested. Indeed, positive relationships between winter temperatures and copepod stocks have already been described by Colebrook (1982, 1984, 1985), Roff et al. (1988) and Fromentin \& Planque (1996); hence, this would be reasonable.

Since no other explanation was found, the logabundances of Temora longicornis were simply correlated to local water temperatures (LT). Weekly, 1-, 2-, 3-, 4-, 5- and 6-mo averages of LT and log-abundance were tested. The highest correlation was obtained for $J$ anuary to March averages of both fields ( $r=0.41$, $p=0.07$ ), which is consistent with the result of the multivariate model (Fig. 7). The correlations are significantly lower or do not exist at all for longer or shorter averages. This does not correspond with the multivariate model, which detected correlations between the NAOI and different averages of T. longicornis (Fig. 7). The reason for this limitation on 3-mo averages-if local temperature data is used-is not known.

In summary, a weak relationship between SST and the abundances of Temora longicornis seems to exists, but it is not convincing. Therefore, the detected correlation remains questionable.

\section{DISCUSSION}

Several authors have discussed interannual variability in marine zooplankton in relation to climate. Aebisher et al. (1990) found parallels between the trends of 'westerly weather' (after the classification scheme of Lamb 1972) and the abundance of phytoand zooplankton. Taylor (1995) showed that a correlation exists between the GSI and the abundance of zooplankton in the eastern Atlantic. Since the time lag between both is less than $1 \mathrm{mo}$, the connection must be via the atmosphere. Fromentin \& Planque (1996) correlated the abundance of 2 Calanus species to the NAOI, which influences wind stress and temperature in Western Europe. Frid \& Huliselan (1996) found high correlations between highly aggregated taxa (i.e. total copepods, first principal component of plankton com- 
munity, total zooplankton) and the GSI. Fock \& Greve (unpubl.) found significant relationships between several phenological plankton variables and the NAOI and GSI.

Whereas the aforementioned studies imply a widely valid relationship between plankton and climate, the 3 presented relationships in this paper are quite specific, i.e. only valid within a narrow time window and for a small part of the population. This difference to the aforementioned studies can be explained by differences in (1) autecology, (2) taxonomic aggregation and (3) abundance versus phenological variables, which will be discussed in the following:

(1) The special autecology concerns the large calanoid copepod Calanus finmarchicus (Fromentin \& Planque 1996), which has a complex biannual life cycle, with overwintering in deep shelf waters and extended winter migrations of pre-adult specimens. During this cycle, $\mathrm{C}$. finmarchicus is highly susceptible to climate driven changes, especially fluctuations in water temperature and changes in the currents.

Species with a less specialized ontogenetic development, such as Temora longicornis, are less susceptible to such changes. The target species in this paper follow an opportunistic life-cycle strategy with the ability to rapidly reproduce and are subject to predatory and other influences, not only in the plankton, but-in the case of the meroplanktonic spionid larvae-in the benthic habitats as well.

(2) If the relationships between climate and plankton are investigated on the level of highly aggregated taxonomic groups, species-specific reaction patterns are smoothed out. Despite the fact that the aggregated data allows no conclusions to be made about single species, the aggregated group generally reveals a more stable behaviour than the single species. This effect is discussed as the 'portfolio effect' in recent ecological literature (Doak et al. 1998, Tilman et al. 1998). Thus, aggregating species can be a method to smooth variability, which might lead to a higher signal to noise ratio, if it is correlated to climate.

(3) Results on the phenological level - such as the start of phanerogame flowering (Maak \& von Storch 1997) or the start of dominance periods (Fock \& Greve unpubl.) - can be predicted with relatively high precision. The reason is that phenological variables depend on physiology and are influenced neither by abundance nor by interaction with other species. In the beginning of the year, climate (temperature, light) often is a limiting factor. Later in the year, it becomes less and less limiting and other factors like species-species interaction and food availablility become dominant.
Acknowledgements. We thank Uwe Lange, Stefan Güss and Hans von Storch for helpful discussions of the results. For their open provision of data, we are indebted to G. A. Becker (BSH, SST data), M. Bergemann (ARGE, Elbe data), J . Hurrel (NCAR, NAO data), A. H. Taylor (GSI data), CRU (T data) and NCAR (SLP data). This project was funded by the Deutsche Forschungsgemeinschaft (DFG), projects STO 321/1-1 (Heyen) and GR 382/3-1 (Fock).

\section{LITERATURE CITED}

A ebisher NJ , Coulsen J C, Colebrook J M (1990) Parallel longterm trends across four marine trophic levels and weather. Nature 347:753-755

Backhaus J O (1980) Simulation von Bewegungsvorgängen in der Deutschen Bucht. Dtsch Hydrogr Z Suppl 15B:7-56

Backhaus J O (1993) Das 'Wetter' im Meer: Nord- und Ostsee. In: Schellnhuber HJ, Sterr H (eds) Klimaänderung und Küste. Springer-Verlag, Berlin, p 37-49

Becker GA, Pauly M (1996) Sea surface temperature changes in the North Sea and their causes. ICES J Mar Sci 53: 887-898

Blackmon ML (1976) A climatological spectral study of the 500 mbar geopotential height of the northern hemisphere. J Atmos Sci 33:1607-1623

Colebrook J M (1982) Continous plankton records: persistence in time-series and the population dynamics of Pseudocalanus elongatus and A cartia clausi. M ar Biol 66:289-294

Colebrook JM (1984) Continous plankton records: relationship between species of phytoplankton and zooplankton in the seasonal cycle. Mar Biol 83:313-323

Colebrook J M (1985) Continous plankton records: overwintering and annual fluctuations in the abundance of zooplankton. Mar Biol 84:261-265

Dippner JW (1995) Untersuchung transienter Wirbelstrukturen in der Deutschen Bucht. Ber Zentrum Meeres- Klimaforsch Univ Hamburg B 18:1-146

Dippner J W (1997) A note on SST anomalies in the North Sea in relation to the North Atlantic Oscillation and the potential influence on the theoretical spawning time of fish. Dtsch Hydrogr Z 49:267-275

Doak DF, Bigger D, Harding EK, Marvier MA, O'Malley RE, Thomas D (1998) The statistical inevitability of stabilitydiversity relationships in community ecology. Am $\mathrm{N}$ at 151: 264-276

Elbrächter M, Qi YZ (1998) Aspects of Noctiluca (Dinophyceae) population dynamics. In: Anderson DM, Cemballa AD, Hallegraeff GM (eds) Physiological ecology of harmful algal blooms. Springer-Verlag, Berlin, p 315-335

Frid CLJ , Huliselan NV (1996) Far-field control of long-term changes in Northumberland (NW North Sea) coastal zooplankton. ICES J Mar Sci 53:972-977

Fromentin J M, Planque B (1996) Calanus and environment in the eastern North Atlantic. II. Influence of the North Atlantic Oscillation on C. finmarchicus and C. helgolandicus. Mar Ecol Prog Ser 134:111-118

Greve W, Reiners F (1995) Biocoenotic process patterns in the German Bight. In: Eleftheriou A, Ansell A, Smith CJ (eds) Biology and ecology of shallow coastal waters. Proc 28th Eur $\mathrm{M}$ ar Biol Symp. OIsen and Olsen, Fredensborg, p 67-71

Heyen H, Dippner JW (1998) Salinity variability in the German Bight in relation to climate variability. Tellus 50A: 545-556

Heyen H, Zorita E, von Storch H (1996) Statistical downscaling of monthly mean North Atlantic air-pressure to sea level anomalies in the Baltic Sea. Tellus 48A:312-323 
Hurrell J W (1995) Decadal trends in the North Atlantic Oscillation: regional temperatures and precipitation. Science 269:676-679

J obson J D (1992) Applied multivariate analysis. Vol II: Categorical and multivariate methods. Springer-Verlag, New York

J ones PD (1994) Hemispheric surface air temperature variations: a reanalysis and an update to 1993. J Clim 7: 1794-1802

Krause M, Dippner JW, Beil J (1995) A review of hydrographic controls on the distribution of zooplankton biomass and species in the North Sea with particular reference to a survey in J anuary-M arch 1987. Prog Oceanogr 35:81-125

Krause M, M artens P (1990) Distribution patterns of mesozooplankton biomass in the North Sea. Helgol Meeresunters 44:295-327

Kröncke I, Dippner J W, Heyen H, Zeiss B (1998) Long-term changes in macrofaunal communities off N orderney (East Frisia, Germany) in relation to climate variability. Mar Ecol Prog Ser 167:25-36

Lamb HH (1972) British Isles weather types and a register of daily sequence of circulation patterns, 1861-1971. Geophys Mem 116, HMSO, London

Livezey RE (1995) The evaluation of forecasts. In: von Storch $\mathrm{H}$, Navarra A (eds) Analysis of climate variability. Springer-Verlag, Berlin, p 177-196

Maak K, von Storch H (1997) Statistical downscaling of monthly mean air temperature to the beginning of flowering of Galanthus nivalis L. in Northern Germany. IntJ Biometeorol 41:5-12

Michaelsen J (1987) Cross-validation in statistical climate forecast models. J Clim Appl Meteorol 26:1589-1600

Preisendorfer RW (1988) Principal component analysis in

Editorial responsibility: Hans von Storch,

Geesthacht, Germany meteorology and oceanography. In: Mobley CD (ed) Development in atmospheric science. Elsevier Science Publishers, Amsterdam, p 1-425

Roff J C, Middlebrook K, Evans F (1988) Long-term variability in North Sea zooplankton off the Northumberland coast: productivity of small copepods and analysis of trophic interactions. J Mar Biol Assoc UK 68:143-164

SAS (1994) SAS/STAT user's guide, Version 6, 4th edn. SAS Inst Inc, Cary, NC

Schaumann K, Gerdes D, Hesse K (1988) Hydrographic and biological characteristics of a N octiluca scintillans red tide in the German Bight, 1984. Meeresforschung 32:77-91

Taylor AH (1995) North-south shifts of the Gulf Stream and their climatic connection with the abundance of zooplankton in the UK and its surrounding seas. ICES J M ar Sci 52: 711-721

Tilman D, Lehman CL, Bristow CE (1998) Diversity-stability relationships: statistical inevitability or ecological consequence. Am Nat 151:277-282

Trenberth KE, Paolino DA J r (1980) The Northern Hemisphere SLP-dataset: trends, errors and discontinuities. Mon Weather Rev 112:1999-2015

Uhlig G, Sahling G (1990) Long term studies on Noctiluca scintillans in the German Bight. Population dynamics and red-tide phenomena 1968-1988. Neth J Sea Res 25: 101-112

von Storch H (1995) Spatial patterns: EOFs and CCA. In: von Storch $\mathrm{H}$, Navarra A (eds) A nalysis of climate variability: applications of statistical techniques. Springer-Verlag, Berlin, p 227-258

von Storch H, Zorita E, Cubasch U (1993) Downscaling of global climate change estimates to regional scales: an application to Iberian rainfall in wintertime. J Clim 6: 1161-1171

Submitted: May 27, 1998; Accepted: August 20, 1998

Proofs received from author(s): November 5, 1998 